\title{
Synthesis, characterization and electrochemical properties of poly (phenoxy-imine)s containing carbazole unit
}

\author{
İsmet Kaya $^{1}$ - Sebra Çöpür ${ }^{1} \cdot$ Hatice Karaer ${ }^{1,2}$
}

Received: 29 June 2016/ Accepted: 11 January 2017/Published online: 27 January 2017

(C) The Author(s) 2017. This article is published with open access at Springerlink.com

\begin{abstract}
Several new Schiff base polymers were synthesized via oxidative polymerization method in an aqueous alkaline medium in the presence of $\mathrm{NaOCl}$ as an oxidant and were confirmed by FT-IR, ${ }^{1} \mathrm{H}-\mathrm{NMR},{ }^{13} \mathrm{C}-\mathrm{NMR}$ and $\mathrm{UV}-\mathrm{V}$ is spectroscopic techniques. Furthermore, cyclic voltammetry measurements were carried out and the HOMO-LUMO energy levels and electrochemical band gaps $\left(E_{\mathrm{g}}{ }^{\prime}\right)$ were calculated. Additionally, the optical band gaps $\left(E_{\mathrm{g}}\right)$ were determined using their $\mathrm{UV}-\mathrm{Vis}$ spectra of the materials. The morphologic properties of the polymers were investigated by scanning electron microscopy. In addition, the number average molecular weight $\left(M_{\mathrm{n}}\right)$, weight average molecular weight $\left(M_{\mathrm{w}}\right)$ and polydispersity index values of the polymers were determined by gel permeation chromatography technique. Electrical conductivity measurements of the doped (with iodine) and undoped polymer related to doping time were carried out by four-point probe technique using a Keithley 2400 electrometer. Their thermal behaviors were determined by TG-DTA and DSC measurements. The synthesized compounds were soluble in common solvents such as DMF, THF and DMSO. Photoluminescence properties of the polymers were determined in different concentrations of DMF solvent.
\end{abstract}

İsmet Kaya

kayaismet@hotmail.com

1 Polymer Synthesis and Analysis Laboratory, Department of Chemistry, Çanakkale Onsekiz Mart University, 17020 Çanakkale, Turkey

2 Department of Chemistry, Faculty of Sciences, Dicle University, 21280 Diyarbakır, Turkey
Keywords Carbazole Fluorescence $\cdot$ Thermal analysis Poly(phenoxy-imine) $\cdot$ Band gaps

\section{Introduction}

Poly(imine)s, known as Schiff base polymers or poly (azomethine)s or also named polyazines (when hydrazine is used as diamine compound) [1] which are of great interest to researchers because of to their potential applications and advantageous properties. Recently, polyazomethines have attracted much attention of both industries and academia and they have been widely investigated for their electrochemical properties, thermal stability, fluorescence, intrinsic conductivity [2].

Polyimines conjugated polymers have claimed the attention of researchers because of their potentially advantageous electronic applications, such as their electrical properties and environmentally stability, with acceptable mechanical strength [3]. Polyazomethines are conducting polymers [4] that usually show an optical absorption band in the visible region owing to their extended delocalization of the $\pi$ electrons along the polymer backbone. Upon doping with suitable dopants, charge carriers, namely bipolaron and polaron, are formed in the conjugated backbone. This class of polymers was primarily found to be electroactive as well as semiconductive materials $[5,6]$, and their conductivity could be increased by doping with a dopant like iodine [2]. Furthermore, Schiff base polymers have been become increasingly interesting in the field of optical materials since they possess great potential for device applications like light-emitting diodes, photovoltaic cells and thin film transistors [7].

Poly(azomethine)s including conjugated bonding and active hydroxyl group have been studied for more than 
60 years, and used in several fields [8]. The oxidative polymerization method is simply the reaction of compounds including $-\mathrm{OH}$ groups and active functional groups $\left(-\mathrm{CHO},-\mathrm{NH}_{2},-\mathrm{COOH}\right)$ in their structure with the oxidants like air oxygen $\mathrm{NaOCl}, \mathrm{H}_{2} \mathrm{O}_{2}$ an in the aqueous alkaline medium [9].

Carbazole-containing polymers are of great interest owing to their several potential for applications in organic electronics, such as organic solar cells, organic field effect transistors (OFET) and organic light-emitting devices (OLED), etc. [10].

In this study, new Schiff bases were synthesized by condensation reaction of 4-diethylaminosalicylaldehyde, 3,4-dihydroxybenzaldehyde and 2,4-dihydroxybenzaldehyde compounds with 3-amino-9-ethyl-carbazole. Then, these products were polymerized via oxidative polycondensation method in an aqueous alkaline medium in the presence of $\mathrm{NaOCl}$ as an oxidant. The structures of all compounds were confirmed by FT-IR, UV-Vis, ${ }^{1} \mathrm{H}-\mathrm{NMR}$ and ${ }^{13} \mathrm{C}$-NMR measurements. Thermal stabilities of all compounds were determined by TG-DTA and DSC measurements. Also, the conductivity and photoluminescence (PL) properties of polymers were determined from fourpoint probe technique and spectrofluorophotometer measurements, respectively.

\section{Experimental}

\section{Materials}

3-Amino-9-ethyl-carbazole, ethyl alcohol, ethyl acetate, chloroform, $\quad N, N$-dimethylacetamide, $\quad N, N$-dimethylformamide, dimethyl sulfoxide, acetonitrile and sodium hypochlorite $(\mathrm{NaOCl}, 37 \%)$ were supplied from Merck Chemical Co. (Germany). 4-Diethylamino salicylaldehyde (Alfa Aesar), 3,4-dihydroxybenzaldehyde (Fluka) and 2,4dihydroxybenzaldehyde were supplied from Acros.

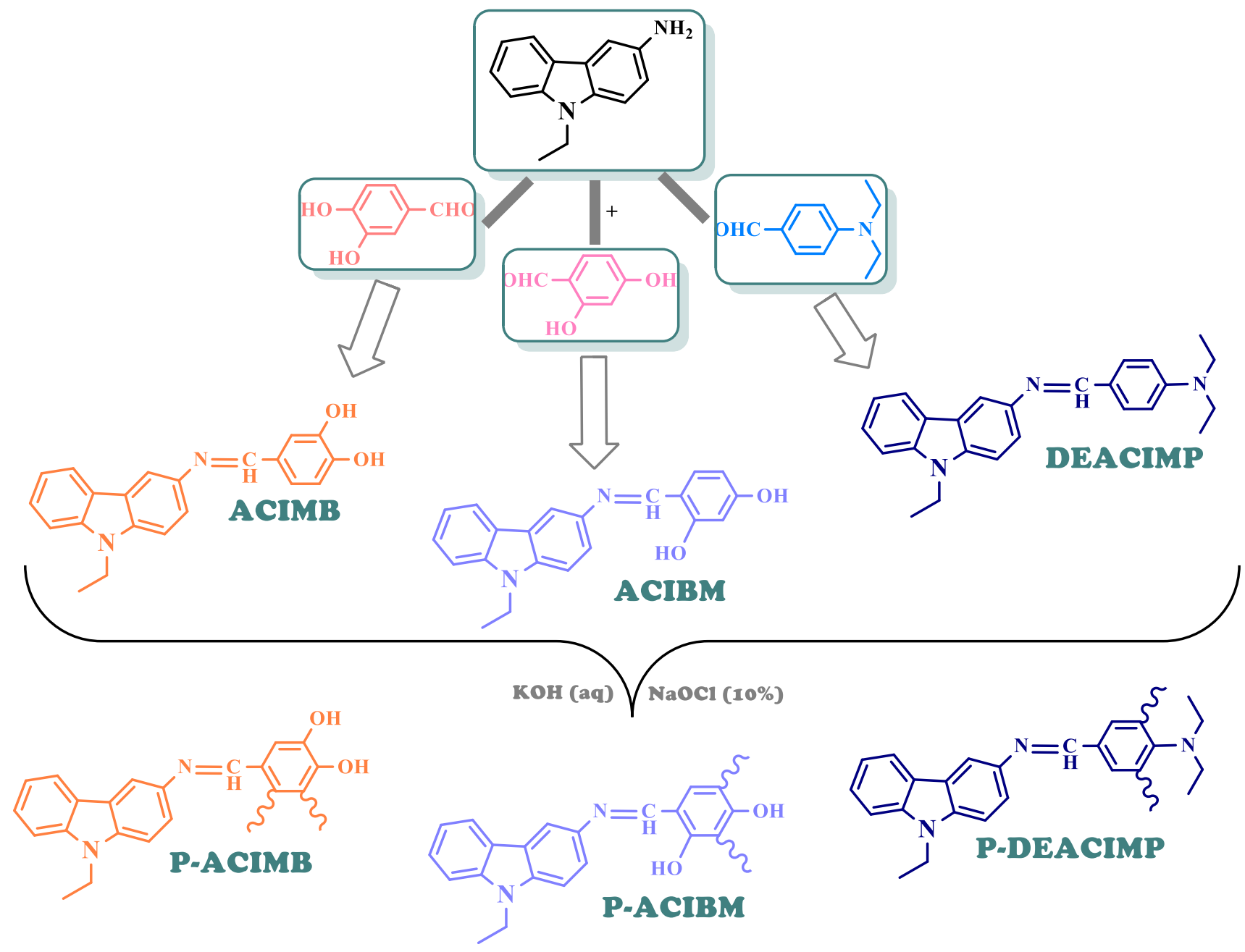

Scheme 1 Syntheses of Schiff bases and their polymers 
Synthesis of the monomers (DEACIMP, ACIMB and $\mathrm{ACIBM)}$

The synthesis of 5-(diethylamino)-2-[(3-amino-9-ethylcarbazole) imino methyl] phenol (DEACIMP) was synthesized according to the literature [11] (Scheme 1) as follows: 4-diethylamino salicylaldehyde $(1.77 \mathrm{~g})$ and 3-amino-9-ethyl-carbazole (1.95 g) were dissolved in $20 \mathrm{~mL}$ absolute ethanol in two separate beakers, which were then mixed. This mixture was refluxed for $5 \mathrm{~h}$ in a two-necked flask and cooled to room temperature. The precipitate formed was filtered, washed with ethanol and then dried under reduced pressure. The same procedure was used to obtain 4-[(3-amino-9-ethyl-carbazole) imino methyl] benzene-1,2-diol (ACIMB) and 4-[(3-amino-9ethyl-carbazolyl) benzene imine methyl]-1,3-diol (ACIBM) the 3,4-dihydroxybenzaldehyde (1.38 g), 3-amino-9-ethyl-carbazole (1.95 g) and 2,4-dihydroxybenzaldehyde (1.38 g), 3-amino-9-ethyl-carbazole (1.95 g) were used for synthesis the ACIMB and ACIBM, respectively. The yields of DEACIMP, ACIMB and ACIBM compounds were found to be $80,85,89$, respectively.

\section{General synthesis procedure of P-DEACIMP, P-ACIMB and P-ACIBM polymers}

P-DEACIMP, P-ACIMB and P-ACIBM were synthesized through the oxidative polycondensation of DEACIMP, ACIMB and ACIBM with aqueous solution of $\mathrm{NaOCl}(10 \%)$. P-DEACIMP was synthesized through oxidative polycondensation of 5-(diethylamino)-2-[(3amino-9-ethyl-carbazole) imino methyl] phenol using aqueous solution of $\mathrm{NaOCl}(10 \%)$. The 5-(diethylamino)-2-[(3-amino-9-ethyl-carbazole) imino methyl] phenol $(0.385 \mathrm{~g})$ was dissolved in an aqueous solution of $25 \mathrm{~mL} \mathrm{KOH} \mathrm{(1.0} \mathrm{M)} \mathrm{placed} \mathrm{into} \mathrm{a} \mathrm{100-mL} \mathrm{three-necked}$ round-bottom flask, which was fitted with a condenser, thermometer. Furthermore, a funnel containing $\mathrm{NaOCl}$, which was added dropwise over about $30 \mathrm{~min}$, was equipped. The reaction mixture was stirred at $100{ }^{\circ} \mathrm{C}$ for $24 \mathrm{~h}$, cooled to room temperature and then $25 \mathrm{~mL} \mathrm{HCl}$ $(1.0 \mathrm{M})$ was added to solution. The P-DEACIMP was washed with water for the separation from mineral salt. The polymers were dried at $60{ }^{\circ} \mathrm{C}$ in an oven for $24 \mathrm{~h}$ $[8,12,13]$.

The same procedure was used to obtain the P-ACIMB and P-ACIBM but the 4-[(3-amino-9-ethyl-carbazole) iminemethylbenzene]-1,2-diol (ACIMB) (0.33 g) and 4-[(3-amino-9-ethyl-carbazole) iminomethylbenzene]-1,3diol (ACIBM) (0.33 g) were used for synthesis the $\mathrm{P}-\mathrm{ACIMB}$ and $\mathrm{P}-\mathrm{ACIBM}$, respectively (Scheme 1). The yields of P-DEACIMP, P-ACIMB and P-ACIBM compounds were found to be $70,72,76$, respectively.

\section{Characterization techniques}

A PerkinElmer spectrum one FT-IR system was used to determine the chemical structure of the monomers and polymers. Measurements were performed in solid powder form at room temperature using universal ATR sampling accessory within the wavelengths of $4000-650 \mathrm{~cm}^{-1}$. UV-Vis spectroscopy, was used to study the electronic transition in the
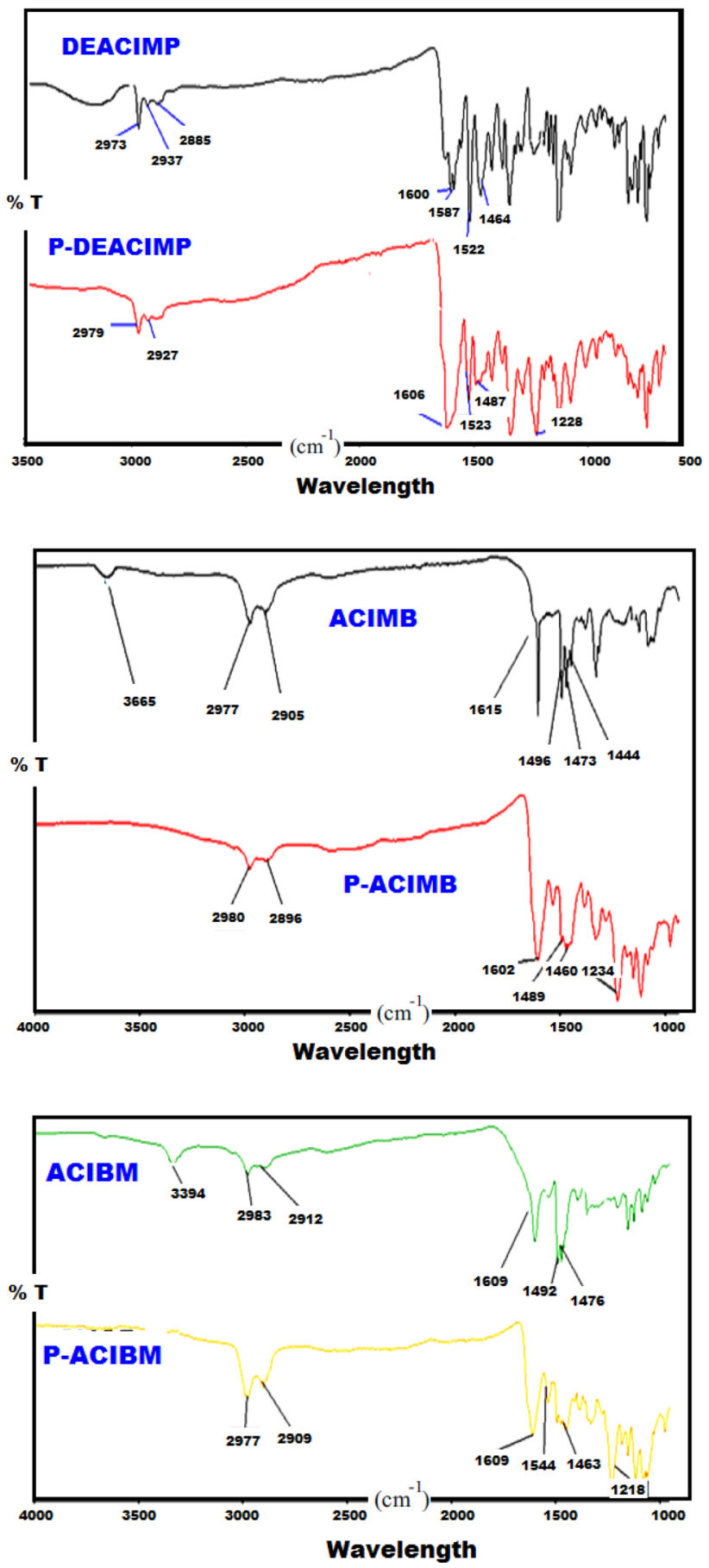

Fig. 1 FT-IR spectra of the monomers and polymers 
Table 1 FT-IR spectral data of monomers and polymers

\begin{tabular}{lllllll}
\hline Compounds & \multicolumn{6}{l}{ Wave number $\left(\mathrm{cm}^{-1}\right)$} \\
\cline { 2 - 7 } & $-\mathrm{OH}$ & $\mathrm{C}-\mathrm{H}$ (aromatic) & $\mathrm{C}-\mathrm{H}$ (aliphatic) & $-\mathrm{C}=\mathrm{N}$ & $\mathrm{C}=\mathrm{C}$ (aromatic) & $\mathrm{C}-\mathrm{O}$ \\
\hline DEACIMP & 3300 & 2973 & 2936 & 1600 & 1587,1522 & - \\
P-DEACIMP & - & 2978 & 2927 & 1604 & 1532,1486 & 1227 \\
ACIMB & 3665 & 2976 & 2905 & 1615 & 1495,1473 & - \\
P-ACIMB & - & 2979 & 2895 & 1602 & 1489,1460 & 1223 \\
ACIBM & 3393 & 2983 & 2911 & 1608 & 1492,1476 & - \\
P-ACIBM & - & 2976 & 2908 & 1608 & 1544,1463 & 1217 \\
\hline
\end{tabular}

UV-Vis region of the all compounds. Measurements were performed by an AnalytikJena Specord 210 Plus with wavelength range of 190-900 $\mathrm{nm}$ by ethyl alcohol solvent at $25^{\circ} \mathrm{C}$. ${ }^{1} \mathrm{H}$ and ${ }^{13} \mathrm{C}$ NMR spectra (Bruker AV400 FT-NMR spectrometer operating at 400.1 and $100.6 \mathrm{MHz}$, respectively) were also recorded in DMSO- $\mathrm{d}_{6}$ at $25^{\circ} \mathrm{C}$. The tetramethylsilane was used as internal standard. Thermal data were obtained by using a PerkinElmer diamond thermal analysis system. TGA-DTA measurements were performed between 20 and $1000{ }^{\circ} \mathrm{C}$ (in $\mathrm{N}_{2}$, rate $10{ }^{\circ} \mathrm{C}$ min $^{-1}$ ). DSC analyses of polymers were carried out by a PerkinElmer Pyris sapphire DSC. DSC measurements were conducted between 25 and $450{ }^{\circ} \mathrm{C}$ (in $\mathrm{N}_{2}$, rate $10{ }^{\circ} \mathrm{C} \min ^{-1}$ ). The number average molecular weight $\left(M_{\mathrm{n}}\right)$, weight average molecular weight $\left(M_{\mathrm{w}}\right)$ and polydispersity index (PDI) were determined by gel permeation chromatography-light scattering (GPC-LS) device by Malvern Viscotek GPC Dual 270 max. For GPC investigations a medium $300 \times 8.00 \mathrm{~mm}$ dual column light scattering detector (LS) and a refractive index detector (RID) were used to analyze the products at $55^{\circ} \mathrm{C}$. $\mathrm{LiBr}(40 \mathrm{mM})$ was added to the DMF mobile phase to dissociate molecular aggregates of polymer during GPC analysis. Surface morphology of the polymers was determined by scanning electron microscope (SEM) (JEOL, JSM-7100 model). Cyclic voltammetry $(\mathrm{CV})$ measurements were carried out with a $\mathrm{CH}$ $660 \mathrm{C}$ Electrochemical Analyzer (CH Instruments, Texas, USA) at a potential scan rate of $20 \mathrm{mV} / \mathrm{s}$. A Shimadzu RF5301PC spectrofluorophotometer was used in fluorescence measurements. Emission spectra of the synthesized polymers were obtained in different concentration of DMF solvent. Also, to obtain maximal emission intensity values of polymers were investigated in different concentrations of DMF solutions.

\section{Results and discussion}

\section{Structural characterization of the monomers and polymers}

The structures of the monomers and polymers were confirmed by FT-IR, ${ }^{1} \mathrm{H}$ and ${ }^{13} \mathrm{C}$-NMR spectra. FT-IR spectra of the monomers and polymers are shown in Fig. 1. According to these spectra, the characteristic peaks such as etheric groups, aromatic and aliphatic $\mathrm{C}-\mathrm{H}$ stretching peaks are observed, as expected. The peaks related to $\mathrm{Ar}-\mathrm{O}$ bonds are in the range of $1217-1235 \mathrm{~cm}^{-1}$ [14], indicating that the polymerization was achieved. The bands due to hydroxyl groups $(-\mathrm{OH})$ are observed at around 3300$3670 \mathrm{~cm}^{-1}$ (Fig. 1) [15].

Aromatic - $\mathrm{CH}$ peaks were observed at around $2980 \mathrm{~cm}^{-1}$ for all the compounds. Furthermore, peaks at $1450-1650 \mathrm{~cm}^{-1}$ were assigned to benzene ring and $(\mathrm{C}=\mathrm{C})$ moiety and those at $1522-1590 \mathrm{~cm}^{-1}$ were attributed to $(\mathrm{C}-$ O) stretching [16] while peaks for aliphatic group were seen at $2900-2940 \mathrm{~cm}^{-1}$.

The peak at $1600-1620 \mathrm{~cm}^{-1}$ corresponds to $-\mathrm{CH}=\mathrm{N}$ stretching vibration of imine moiety. The peaks of vibration bonding are also shown in Table 1. As seen in Fig. 1, peaks of polymers were broader than that of monomers after the polycondensation reaction owing to their polyconjugated structures. Other characteristic absorption bands are also presented in Table 1.

Furthermore, the edged peaks of P-DEACIMP, P-ACIMB and P-ACIBM were broader and decreased numerically due to the increase in molecular weight after polymerization reactions [17], confirming polymerization of DEACIMP, ACIMB and ACIBM.

${ }^{1} \mathrm{H}$ NMR and ${ }^{13} \mathrm{C}$ NMR spectra of the monomers and polymers were recorded in DMSO- $\mathrm{d}_{6} \cdot{ }^{1} \mathrm{H}$ data of the monomers and polymers are listed in Table 2 and the spectrum of a representative polymer P-DEACIMP and DEACIMP are shown in Fig. 2. The ${ }^{1} \mathrm{H}$ and ${ }^{13} \mathrm{C}$ NMR spectra of DEACIMP and P-DEACIMP data are given in Figs. 2 and $3 .{ }^{1} \mathrm{H}$ and ${ }^{13} \mathrm{C}$ NMR data results of the synthesized compounds are listed in Table 2 except for DEACIMP and P-DEACIMP. When phenol-based Schiff bases were polymerized by oxidative polycondensation, they were combined by $\mathrm{C}-\mathrm{C}$ binding at ortho and/or para position of the ring or alternatively $\mathrm{C}-\mathrm{O}-\mathrm{C}$ binding through oxygen atom of -OH moiety (Scheme 1) [2, 18]. ${ }^{1} \mathrm{H}-\mathrm{NMR}$ spectra of the polymers contained three types of signals assigned as follows: the singlet at $8.05-8.98 \mathrm{ppm},-\mathrm{CH}=\mathrm{N}-$; the multiple at $6.40-8.50 \mathrm{ppm}$, aromatic protons. The proton resonances 
Table 2 NMR spectra data of the monomers and polymers

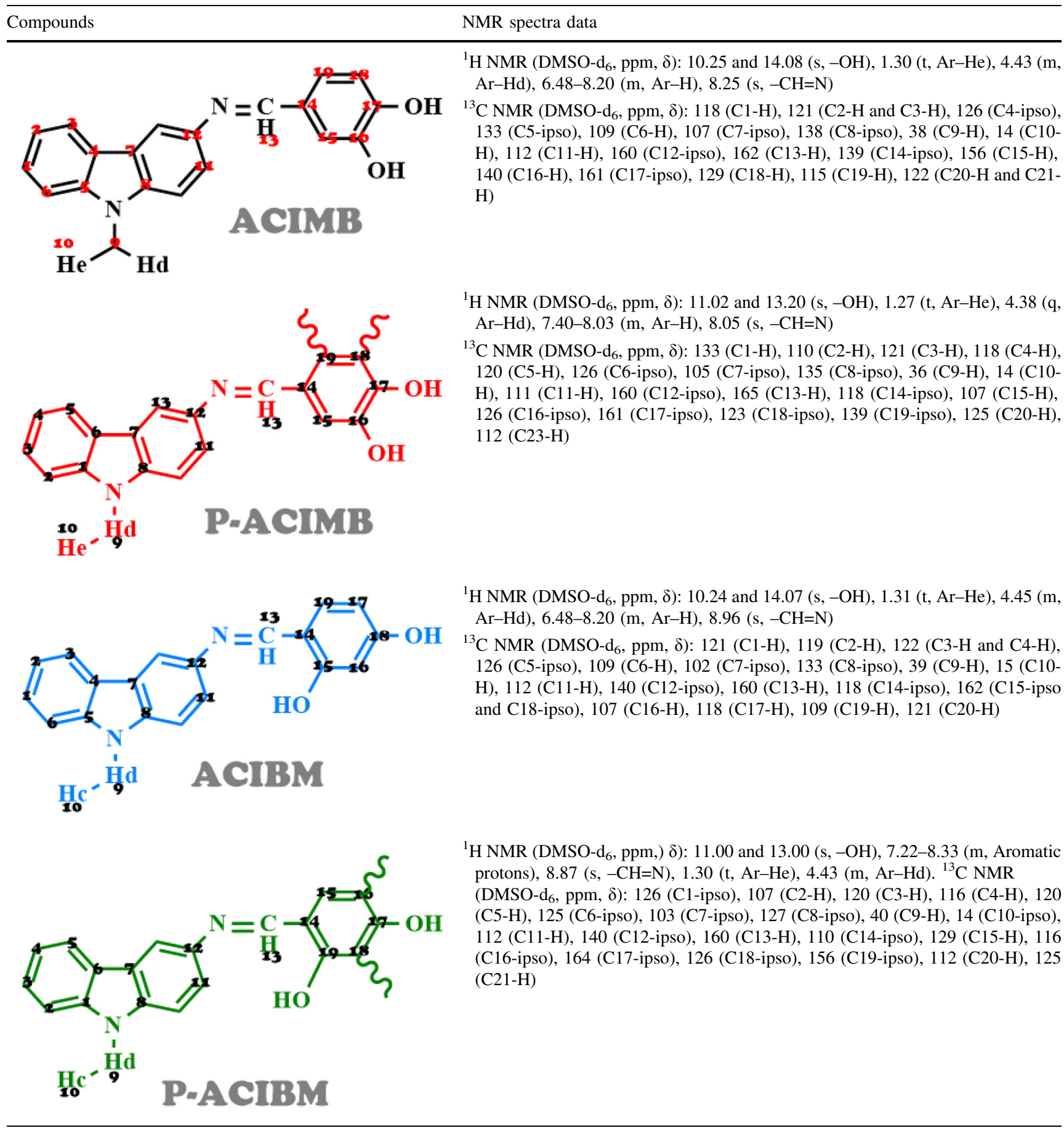

of hydroxyl $(-\mathrm{OH})$ groups were observed at 12.01, 10.25 and 14.08, 10.24 and $14.07 \mathrm{ppm}$ for DEACIMP, ACIMB and ACIBM, respectively. The proton signal of hydroxyl ($\mathrm{OH})$ groups were observed at 12.85, 11.02 and 13.20, 11.00 and $13.00 \mathrm{ppm}$ for P-DEACIMP, P-ACIMB and P-ACIBM, respectively. Meanwhile, the FT-IR spectra of polymers show bands in 1217,1223 and $1227 \mathrm{~cm}^{-1}$ is assignable to the phenolic $\mathrm{C}-\mathrm{O}$ stretching vibration [2].
The azomethine protons are observed in $8.84,8.25$ and $8.96 \mathrm{ppm}$ for DEACIMP, ACIMB and ACIBM monomers, 8.90, 8.05 and $8.87 \mathrm{ppm}$ for P-DEACIMP, P-ACIMB and P-ACIBM polymers, respectively. The ${ }^{1} \mathrm{H}$ NMR spectra of polymers shows broad signals for aromatic protons which confirm the participation of aromatic ring in polymerization $[2,19]$. New signals were observed in the region of 169, 162 and $168 \mathrm{ppm}$ in the ${ }^{13} \mathrm{C}$ NMR spectra of 


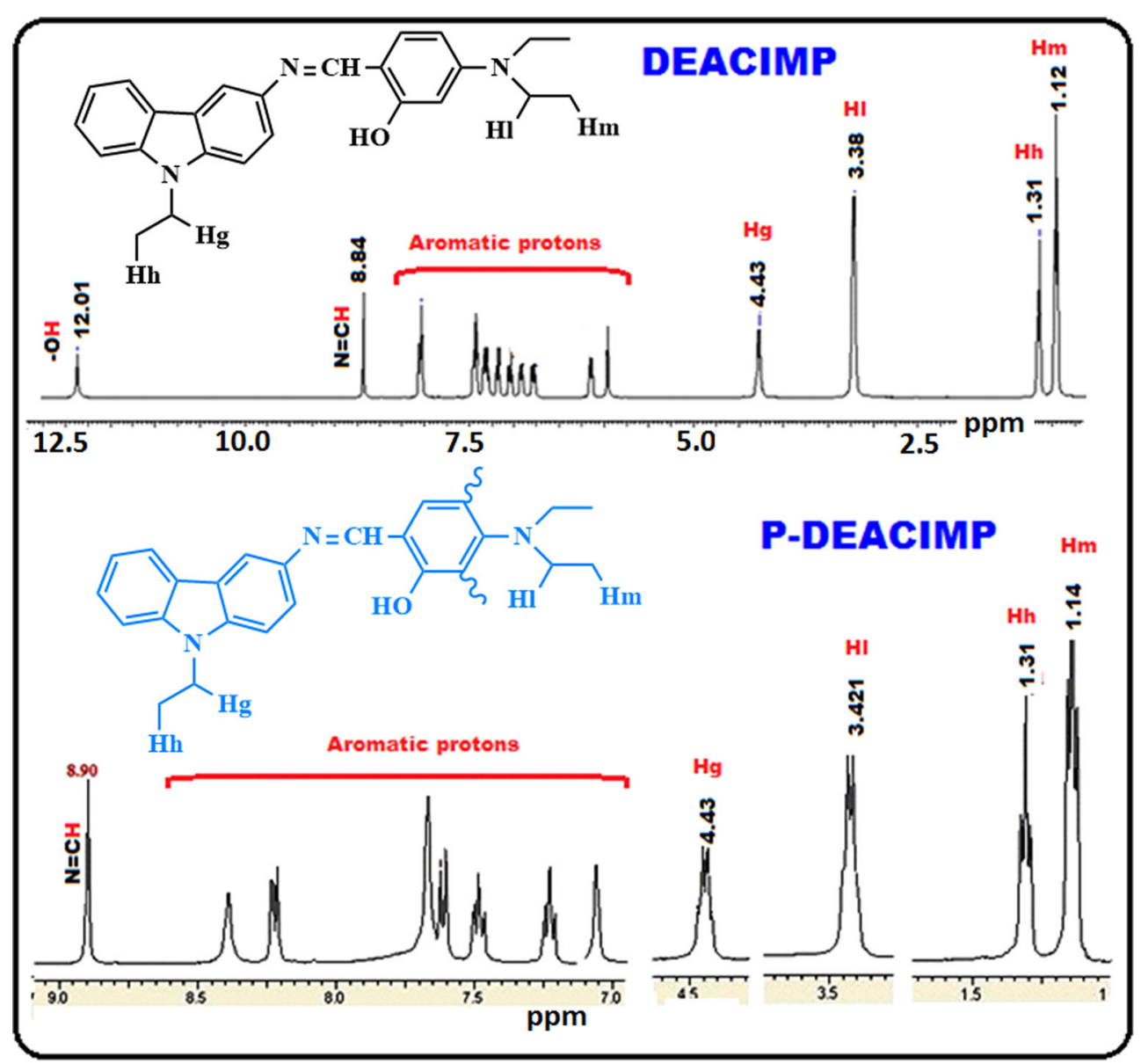

Fig. $2{ }^{1} \mathrm{H}$ NMR spectra of DEACIMP and P-DEACIMP

P-DEACIMP, P-ACIMB and P-ACIBM, respectively, due to $-\mathrm{C}-\mathrm{O}-\mathrm{C}-$ coupling, confirming polymerization occurred via $-\mathrm{OH}$ moiety [20].

Appearance of the new short resonances at 109,148 and 135,139 ppm obviously indicate polymerization of DEACIMP, ACIMB and ACIBM, respectively, i.e., $-\mathrm{C}-\mathrm{C}$ binding occurs at ortho or para position of phenol by distribution of the phenoxy radical to the ring. The azomethine and aromatic carbon signals were observed at 159 and 97-163, 162 and $107-161,160$ and $102-162 \mathrm{ppm}$ in the ${ }^{13} \mathrm{C}$ NMR spectra of DEACIMP, ACIMB and ACIBM, respectively. Thus, we can easily conclude that the NMR data confirming the structures of the aimed products.

\section{GPC analysis of polymers}

Gel permeation chromatography (GPC) analyses of compounds (P-DEACIMP, P-ACIBM and P-ACIMB) were performed at $55{ }^{\circ} \mathrm{C}$ by DMF as eluent at a flow rate of $1.0 \mathrm{~mL} \mathrm{~min}^{-1}$. The number average molecular weight $\left(M_{\mathrm{n}}\right)$, weight average molecular weight $\left(M_{\mathrm{w}}\right)$ and polydispersity index (PDI, $M_{\mathrm{w}} / M_{\mathrm{n}}$ ) values of compounds were calculated according to a polystyrene standard calibration curve. The weight average molecular weight $\left(M_{\mathrm{w}}\right)$ and polydispersity index (PDI, $M_{\mathrm{w}} / M_{\mathrm{n}}$ ) values of P-DEACIMP, P-ACIBM and P-ACIMB were found to be 8350,6400 , and 9200 and 1.25 , 1.22 and 1.27 , respectively. These results also agree with the solubility tests. P-ACIBM had lower molecular weight than P-DEACIMP and P-ACIMB polymers. So it was a fine-soluble polymer in common organic solvents and the others had lower solubilities owing to their high-molecular weighted structures.

\section{Optical properties of compounds}

UV-Vis spectra of the compounds recorded in ethyl alcohol at room temperature are given in Fig. 4. Their optical band gaps $\left(E_{\mathrm{g}}\right)$ were calculated as in the literature [21] and results are shown in Table 3.

$E_{\mathrm{g}}=1242 / \lambda_{\text {onset }}$,

where $\lambda_{\text {onset }}$ is the onset wavelength which may be determined by intersection of two tangents on the absorption edges. $\lambda_{\text {onset }}$ also indicates the electronic transition start wavelength. According to results, one can easily conclude 
Fig. $3{ }^{13} \mathrm{C}$ NMR spectra of DEACIMP and P-DEACIMP
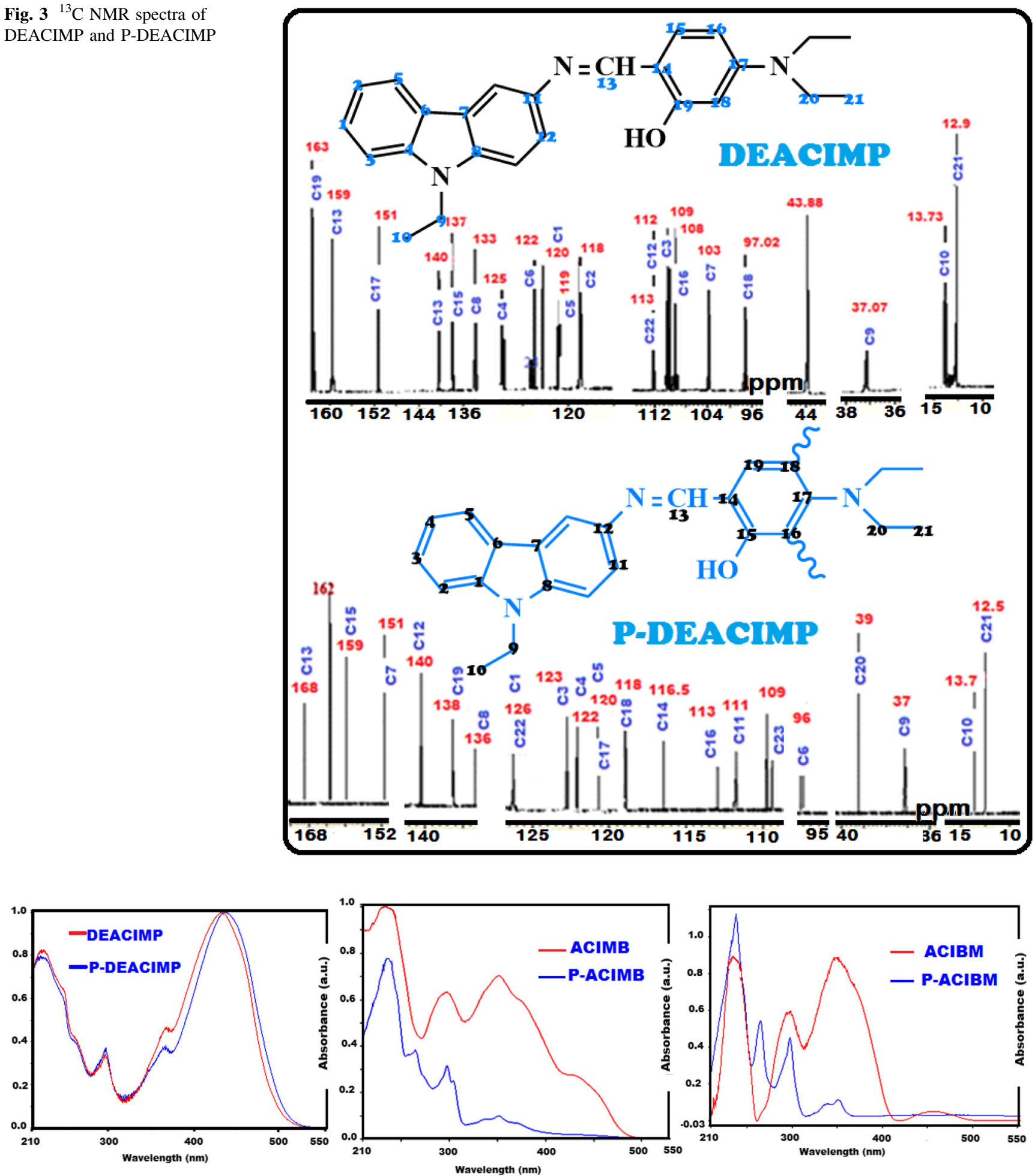

Fig. 4 Absorption spectra of the monomers and polymers (conc.: $100 \mathrm{mg} \mathrm{L}^{-1}$ in ethyl alcohol solvent)

that the polymers have low optical band gaps. Because of monomers and polymers compounds to be having the same functional groups, some UV-Vis absorption bands of their were observed as similar.
It is known that the solubility behavior is very advantageous for the processing of these materials for technological applications [4]. Thus, the solubility properties of the polymers and monomers were tested in 
Table 3 Optical electronic structure parameters of the monomers and polymers

\begin{tabular}{llllllll}
\hline Compound & $E_{\mathrm{g}}^{\mathrm{a}}(\mathrm{eV})$ & $\lambda_{\text {onset }}(\mathrm{nm})$ & $E_{\mathrm{ox}}^{\mathrm{b}}(\mathrm{eV})$ & $E_{\mathrm{red}}^{\mathrm{c}}(\mathrm{eV})$ & $\mathrm{HOMO}^{\mathrm{d}}(\mathrm{eV})$ & $\mathrm{LUMO}^{\mathrm{e}}(\mathrm{eV})$ & $E_{\mathrm{g}}{ }^{\mathrm{f}}(\mathrm{eV})$ \\
\hline DEACIMP & 2.43 & 510 & 1.44 & -1.73 & -5.83 & -2.66 & 3.17 \\
P-DEACIMP & 2.41 & 515 & 1.28 & -1.30 & -5.67 & -3.09 & 2.58 \\
ACIMB & 2.60 & 478 & 1.32 & -1.29 & -5.71 & -3.10 & 2.60 \\
P-ACIMB & 3.13 & 396 & 1.29 & -1.23 & -5.68 & -3.16 & 2.51 \\
ACIBM & 3.05 & 406 & 0.92 & -1.33 & -5.31 & -3.06 & 2.25 \\
P-ACIBM & 3.01 & 412 & 0.80 & -0.74 & -5.19 & -3.65 & 1.54 \\
\hline
\end{tabular}

${ }^{a}$ Optical band gap

b Oxidation peak potential

${ }^{c}$ Reduced peak potential

${ }^{d}$ Highest occupied molecular orbital

e Lowest unoccupied molecular orbital

${ }^{\mathrm{f}}$ Electrochemical band gap

\begin{tabular}{lllllll}
\hline Solvent & DEACIMP & ACIMB & ACIBM & P-DEACIMP & P-ACIMB & P-ACIBM \\
\hline DMF & + & + & + & + & + & + \\
DMA & + & + & + & + & + & + \\
DMSO & + & + & + & + & + & + \\
THF & + & + & + & + & + & + \\
Ethyl acetate & + & + & + & $\perp$ & - & - \\
Chloroform & + & + & + & $\perp$ & $\perp$ & $\perp$ \\
Acetone & + & + & + & $\perp$ & $\perp$ & $\perp$ \\
Ethanol & + & + & + & $\perp$ & $\perp$ & $\perp$ \\
Acetonitrile & + & + & + & $\perp$ & $\perp$ & + \\
\hline
\end{tabular}

$(+)$, soluble; $(\perp)$, partially soluble; $(-)$, insoluble
Table 4 Solubility characteristics of the monomers and polymers $\left(1 \mathrm{mg} \mathrm{mL}^{-1}\right)$ at $25{ }^{\circ} \mathrm{C}$ different solvents by using $1 \mathrm{mg}$ of compound in $1 \mathrm{~mL}$ solvent and shown in Table 4.

Fluorescence properties of the synthesized compounds are determined using DMF solutions at different concentrations [22]. Also, the optimization of the concentrations to obtain maximal emission intensity is investigated in DMF. Concentration effects on the fluorescence properties are shown in Fig. 5. Maximum emission intensity values of the compounds are also given in Table 5. When concentration of DEACIMP, P-DEACIMP, ACIMB were decreased, they showed bathochromic shift in the range 14-35 nm. On the other hand, a significant change in the emission wavelength of these polymers was not observed. As seen in Table 5, these results showed that P-ACIMB polymer has higher emission intensity values at $9.76 \times 10^{-6}$ and $1.95 \times 10^{-5} \mathrm{~g} \mathrm{~mL}^{-1}$ than the other synthesized polymers and monomers. But P-DEACIMP and ACIBM have the lowest emission intensity as polymer and monomer, respectively.

Stokes shift $\left(\Delta \lambda_{\mathrm{ST}}\right)$ is the difference between positions of the band maxima of emission and excitation spectra of the same electronic transition. This knowledge offers significant conformational differences between ground state $\left(S_{0}\right)$ and the first excited state $\left(S_{1}\right)$. If the $\Delta \lambda_{\mathrm{ST}}$ value is too small, the emission and excitation spectra will overlap more. So the emitted light will be self-absorbed and the photoluminescence efficiency will decrease. $\Delta \lambda_{\mathrm{ST}}$ values are listed in Table 5. $\Delta \lambda_{\mathrm{ST}}$ values of P-DEACIMP, P-ACIMB and P-ACIBM are calculated as 48, 31 and 61, respectively. According to $\Delta \lambda_{\mathrm{ST}}$ values, the synthesized $\mathrm{P}$-ACIBM can be used for the production of fluorescence sensor owing to high $\Delta \lambda_{\mathrm{ST}}$ value [23]. It can be seen from Fig. 5 that with increase in the concentrations of the solutions, the absorption spectra of the compounds were observed to shift to the visible region.

\section{Thermal properties of the polymers}

Thermal degradation data (TGA-DTA and DTG) are listed in Table 6. TGA curves of the synthesized monomers and polymers are also shown in Fig. 6. According to the TGA results, the initial degradation temperatures $\left(T_{\mathrm{on}}\right)$ of the monomers are higher than their polymers, expect for P-ACIBM. This could be explained by the formation of C- 

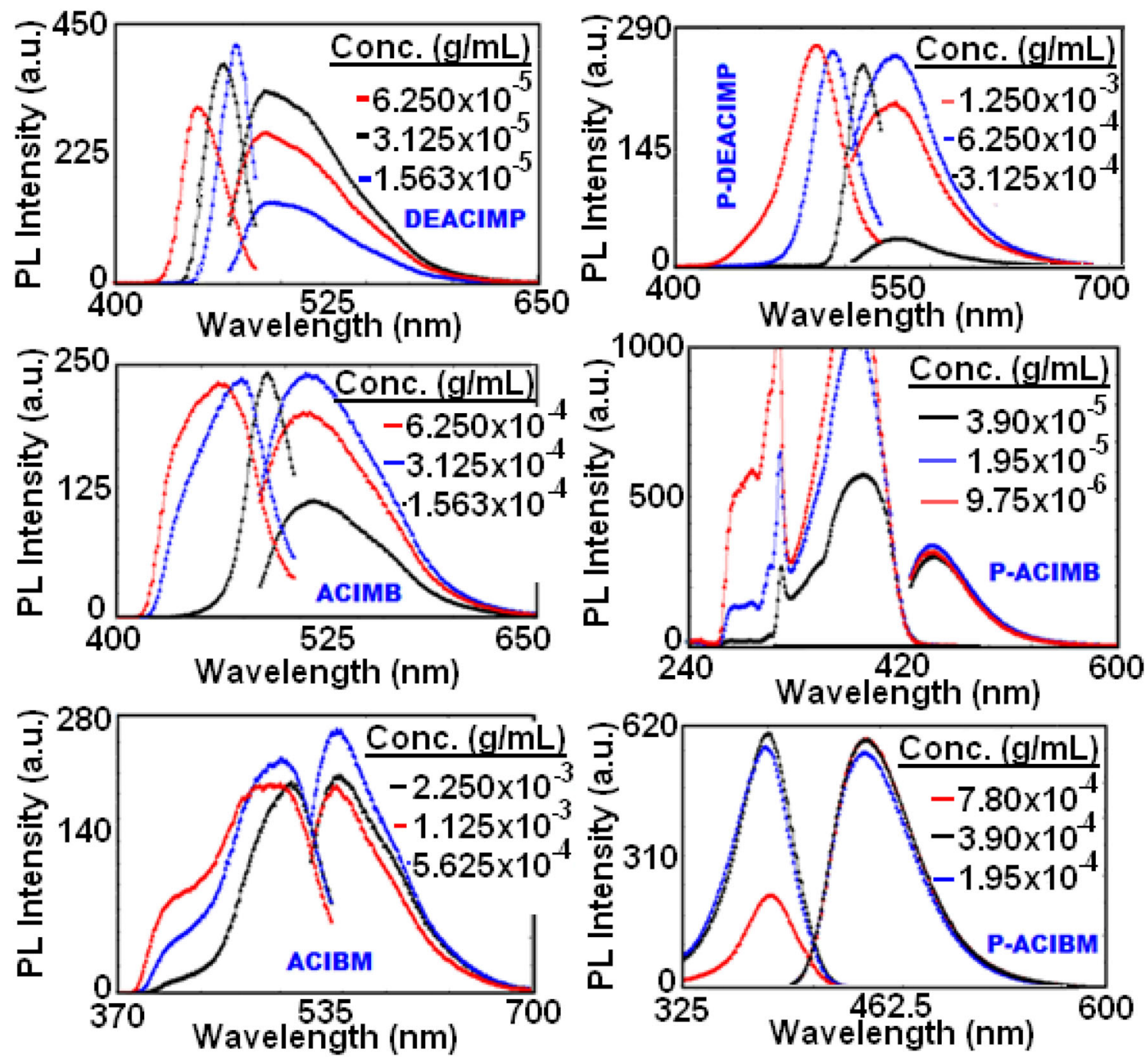

Fig. 5 Emission spectra of the synthesized monomers and polymers in different concentrations ( $P L$ intensity photoluminescence intensity, slit width: $3 \mathrm{~nm}$, in DMF solvent)

$\mathrm{O}$ etheric bond during polymerization. This weak bond is easily broken at mild temperatures and makes the polymer thermally unstable [21, 22]. Furthermore, when \% char amounts are compared, \% char of ACIMB was higher than other compounds at $1000{ }^{\circ} \mathrm{C}$. In addition, Table 6 exhibits listed temperatures corresponding to 5, 10, 20 and $50 \%$ weight losses of the all compounds. $T_{\text {on }}$ values of monomers and polymers were found between 219-320 and 201$230{ }^{\circ} \mathrm{C}$, respectively. According to TG curves of ACIMB, ACIBM, P-DEACIMP, P-ACIMB, and P-ACIBM, the losses of absorbed water were found to be 2, 1.7, 2.7, 5.1 and $3.9 \%$, respectively, between 20 and $150^{\circ} \mathrm{C}$. DEACIMP monomer was degraded at the one step between 320 and $540{ }^{\circ} \mathrm{C}$ and its weight loss was $86.5 \%$ at this step. ACIMB and ACIBM monomers were degraded in two steps: between 220-385 and 219-308 for the first step; 385-690 and $308-665^{\circ} \mathrm{C}$ for the second step and their weight losses were 23, 16; 21 and $35 \%$ at these steps, respectively. P-DEACIMP, P-ACIMB and P-ACIBM polymers were degraded in two steps: between 230-370, 209-380 and 201-620 for the first step; 370-570, 380-600 and 620$1000{ }^{\circ} \mathrm{C}$ for the second step and their weight losses were $53,37,50 ; 25,22$ and $14 \%$ at these steps, respectively.

According to DSC measurements of polymers, the $T_{\mathrm{g}}$ and $C_{\mathrm{p}}$ values of P-DEACIMP, P-ACIMB, and P-ACIBM were found to be 123,105 and $104{ }^{\circ} \mathrm{C}$ and $2.083,0.086$, and $0.075 \mathrm{~J} \mathrm{~g}^{-1} \mathrm{~K}^{-1}$, respectively. The results indicated that P-DEACIMP has the highest $T_{\mathrm{g}}$.

\section{Morphologic properties}

Morphological properties of the polymers are obtained by SEM technique. SEM images of compounds were recorded using a Jeol JSM-7100F Schottky instrument in a powder 
Table 5 The maximum emission intensity values that obtained from fluorescence spectra of the monomers and polymers as a function of concentration

\begin{tabular}{|c|c|c|c|c|c|c|c|c|}
\hline Compounds & Concentration $\left(\mathrm{mg} \mathrm{mL}^{-1}\right)$ & ${ }^{\mathrm{a}} \chi_{\mathrm{ex}}(\mathrm{nm})$ & ${ }^{\mathrm{b}} \lambda_{\mathrm{em}}(\mathrm{nm})$ & ${ }^{\mathrm{c}} \lambda_{\max (\mathrm{ex})}(\mathrm{nm})$ & $\mathrm{d}_{\chi_{\max (\mathrm{em})}(\mathrm{nm})}$ & ${ }^{\mathrm{e}} I_{\mathrm{ex}}$ & ${ }^{\mathrm{f}} I_{\mathrm{em}}$ & ${ }^{\mathrm{g}} \Delta \lambda_{\mathrm{ST}}$ \\
\hline \multirow[t]{3}{*}{ DEACIMP } & $6.250 \times 10^{-5}$ & 460 & 496 & 450 & 495 & 305 & 260 & 35 \\
\hline & $3.125 \times 10^{-5}$ & 460 & 496 & 467 & 495 & 378 & 332 & 35 \\
\hline & $1.563 \times 10^{-5}$ & 460 & 496 & 473 & 495 & 412 & 140 & 35 \\
\hline \multirow[t]{3}{*}{ P-DEACIMP } & $1.250 \times 10^{-3}$ & 513 & 555 & 498 & 561 & 272 & 200 & 48 \\
\hline & $6.250 \times 10^{-4}$ & 513 & 555 & 512 & 561 & 264 & 258 & 48 \\
\hline & $3.125 \times 10^{-4}$ & 513 & 555 & 532 & 561 & 247 & 34 & 48 \\
\hline \multirow[t]{3}{*}{ ACIMB } & $6.250 \times 10^{-4}$ & 475 & 514 & 460 & 515 & 243 & 117 & 60 \\
\hline & $3.125 \times 10^{-4}$ & 475 & 514 & 474 & 515 & 237 & 241 & 60 \\
\hline & $1.563 \times 10^{-4}$ & 475 & 514 & 484 & 515 & 233 & 204 & 60 \\
\hline \multirow[t]{3}{*}{ P-ACIMB } & $3.90 \times 10^{-5}$ & 416 & 478 & 385 & 447 & 574 & 302 & 31 \\
\hline & $1.95 \times 10^{-5}$ & 416 & 478 & 380 & 447 & $>1000$ & 338 & 31 \\
\hline & $9.75 \times 10^{-6}$ & 416 & 478 & 375 & 447 & $>1000$ & 317 & 31 \\
\hline \multirow[t]{3}{*}{ ACIBM } & $2.250 \times 10^{-3}$ & 528 & 568 & 526 & 561 & 233 & 204 & 33 \\
\hline & $1.125 \times 10^{-3}$ & 528 & 568 & 519 & 561 & 237 & 117 & 33 \\
\hline & $5.625 \times 10^{-4}$ & 528 & 568 & 518 & 561 & 243 & 241 & 33 \\
\hline \multirow[t]{3}{*}{ P-ACIBM } & $7.80 \times 10^{-4}$ & 384 & 449 & 381 & 445 & 224 & 589 & 61 \\
\hline & $3.90 \times 10^{-4}$ & 384 & 449 & 380 & 445 & 602 & 586 & 61 \\
\hline & $1.95 \times 10^{-4}$ & 384 & 449 & 379 & 445 & 572 & 558 & 61 \\
\hline
\end{tabular}

${ }^{a}$ Excitation wavelength for emission

b Emission wavelength for excitation

c Maximum emission wavelength

${ }^{\mathrm{d}}$ Maximum excitation wavelength

e Maximum excitation intensity

${ }^{f}$ Maximum emission intensity

g Stokes shift

Table 6 Thermal stabilities of the monomers and polymers

\begin{tabular}{lllllllll}
\hline TGA/DTG DTA \\
\hline Compounds & ${ }^{\mathrm{a}} T_{\text {on }}$ & ${ }^{\mathrm{b}} T_{\max }$ & ${ }^{\mathrm{c}} T_{5}\left({ }^{\circ} \mathrm{C}\right)$ & ${ }^{\mathrm{d}} T_{10}\left({ }^{\circ} \mathrm{C}\right)$ & ${ }^{\mathrm{e}} T_{20}\left({ }^{\circ} \mathrm{C}\right)$ & ${ }^{\mathrm{f}} T_{50}\left({ }^{\circ} \mathrm{C}\right)$ & $\mathrm{g}_{\%}$ char & Endo $\left({ }^{\circ} \mathrm{C}\right)$ \\
\hline DEACIMP & 320 & 367 & 330 & 348 & 359 & 376 & 9.5 & 127,373 \\
P-DEACIMP & 230 & 270,425 & 236 & 248 & 269 & 345 & 20.0 & 129 \\
ACIMB & 220 & 302,478 & 235 & 263 & 351 & - & 54.0 & - \\
P-ACIMB & 209 & 316,432 & 216 & 247 & 298 & 424 & 23.0 & - \\
ACIBM & 219 & 244,419 & 232 & 248 & 315 & 534 & 43.0 & 223 \\
P-ACIBM & 201 & 412,862 & 234 & 298 & 380 & 542 & 35.0 & - \\
\hline
\end{tabular}

\footnotetext{
${ }^{a}$ The onset temperature

b Temperature of the peak maxima

c Temperature corresponding to 5\% weight loss

d Temperature corresponding to $10 \%$ weight loss

e Temperature corresponding to $20 \%$ weight loss

f Temperature corresponding to $50 \%$ weight loss

g \% char at $1000{ }^{\circ} \mathrm{C}$
}

form. Polymers were prepared by sprinkling on doublesided adhesive tape mounted on a carbon stub and then they coated with a thin gold/palladium film by a sputter coater.
SEM photographs of P-DEACIMP, P-ACIBM and P-ACIMB are given in Fig. 7. According to the SEM images, P-ACIBM consists of different, nano-sized particles, while P-ACIMB has sharp edges with the form of 

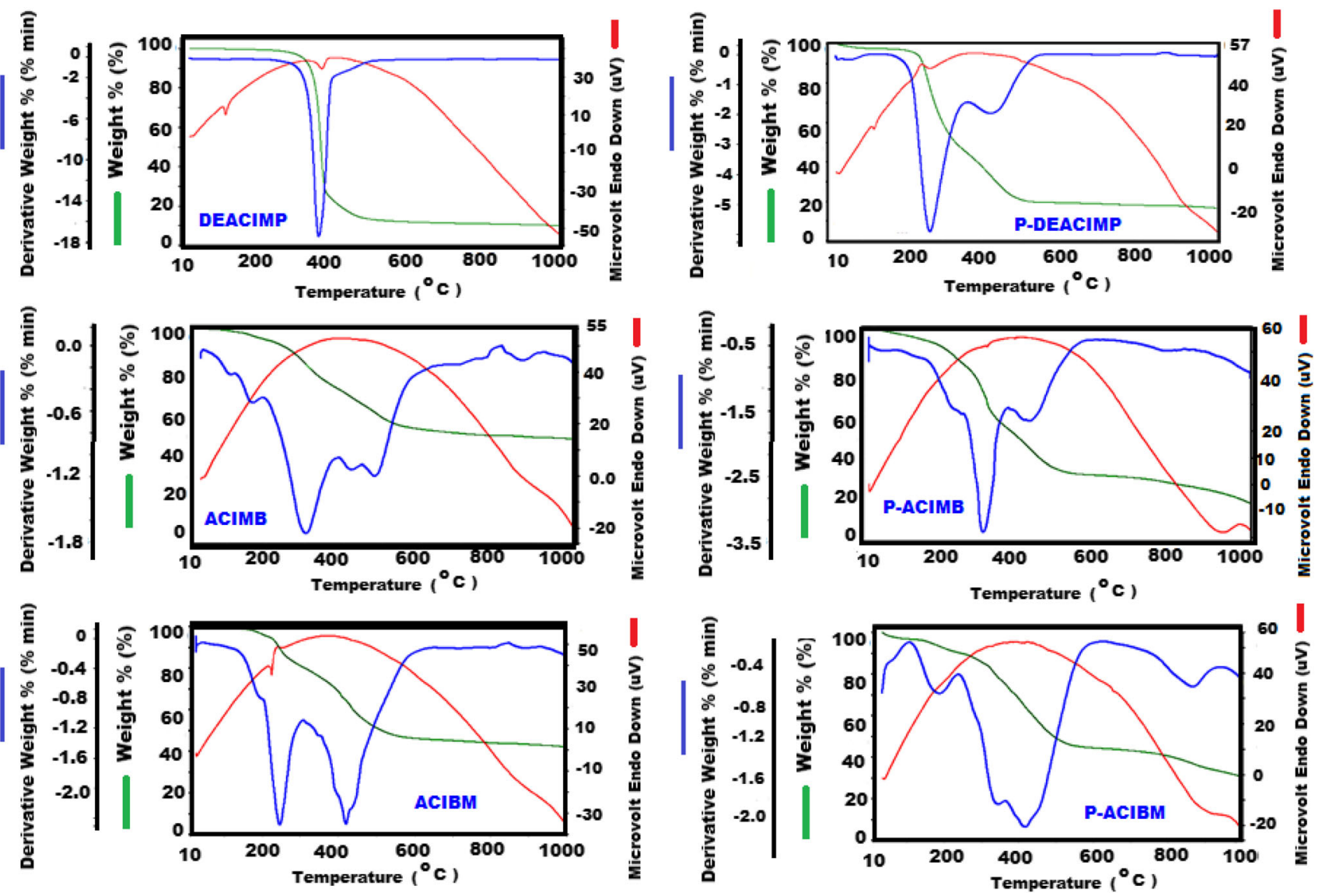

Fig. 6 TGA-DTA-DTG curves of the monomers and polymers (heating rate: $10 \mathrm{C} \min ^{-1} ; \mathrm{N}_{2}$ atmosphere)

rods. Surface of P-DEACIMP has the folds in the form of brain.

\section{Electrochemical and conductivity properties}

The voltammetric measurements were performed in acetonitrile. All the experiments were performed in a dry box filled with $\mathrm{Ar}$ at room temperature. The electrochemical potential of $\mathrm{Ag}$ was calibrated with respect to the ferrocene/ferrocenium $\left(\mathrm{Fc} / \mathrm{Fc}^{+}\right)$couple. The half-wave potential $\left(\mathrm{E}^{1 / 2}\right)$ of $\left(\mathrm{Fc} / \mathrm{Fc}^{+}\right)$measured in $0.1 \mathrm{M}$ tetrabutylammoniumhexafluorophosphate $\left(\mathrm{TBAPF}_{6}\right)$ acetonitrile solution is $0.39 \mathrm{~V}$ with respect to $\mathrm{Ag}$ wire or $0.38 \mathrm{~V}$ with respect to saturated calomel electrolyte (SCE). The voltammetric measurements were carried out for all monomer compounds by acetonitrile and added to extra $1 \mathrm{~mL}$ DMF for polymers.

The values of electrochemical band gaps $\left(E_{\mathrm{g}}{ }^{\prime}\right)$ are given in Table 3. These data were estimated by using the oxidation onset $\left(E_{\text {ox }}\right)$ and reduction onset $\left(E_{\text {red }}\right)$ values, as given in Fig. 8 for the compounds where $E_{\mathrm{ox}}$ is the oxidation peak potential and $E_{\text {red }}$ is the reduction peak potential. The calculations were performed by using the following equations [24]:

$E_{\mathrm{HOMO}}=-\left(4.39+E_{\mathrm{Ox}}\right)$

$E_{\mathrm{LUMO}}=-\left(4.39+E_{\mathrm{red}}\right)$

$E_{\mathrm{g}}^{\prime}=E_{\mathrm{LUMO}}-E_{\mathrm{HOMO}}$.

To understand the electronic structure of conjugated polymers it is essential to establish the relative positions of the characteristic electronic energy levels such as the highest occupied molecular orbital (HOMO or п level), the lowest unoccupied molecular orbital (LUMO or $\pi$ ), and the associated energy parameters $[25,26]$.

The oxidation peaks in cyclic voltammograms probably correspond to the oxidation of hydroxyl groups to form phenoxy radicals. The reduction peaks were presumably due to the reduction of the azomethine linkages via protonation of azomethine nitrogen [23].

According to the Table 3, the order of the electrochemical band gap values of the polymer changes are as follows: P-ACIBM > P-ACIMB > P-DEACIMP. This was a result of the polyconjugated structures of the polymers, 

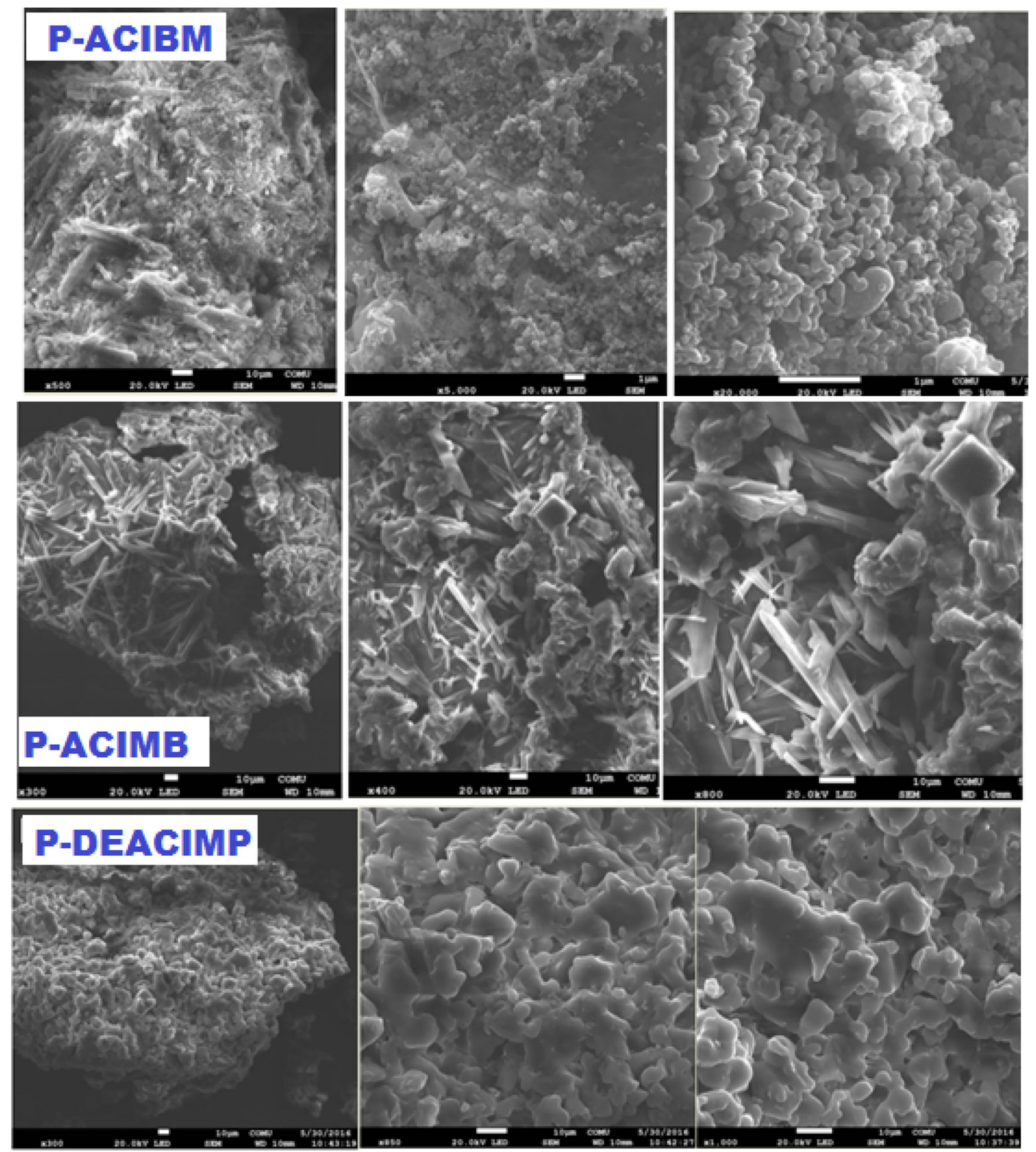

Fig. 7 SEM images of polymers

which increase HOMO and decrease LUMO energy levels, resulting in lower electrochemical band gaps [23].

Conductivity was measured by a Keithley 2400 Electrometer (Keithley, Ohio, USA). The pellets were pressed on hydraulic press at $1687.2 \mathrm{~kg} / \mathrm{cm}^{2}$. Iodine doping was carried out by exposing the pellets to iodine vapor at atmospheric pressure and room temperature in a desiccator. Solid-state conductivities of the polymers measured under air atmosphere were shown in a graph plotted versus time. The measurements for the polymers were carried out in pure form and then polymers were exposed to iodine vapor in a desiccator, and the change in their conductivities depending on time was measured at specific time intervals by doping. In the doping process, electron emitting amine nitrogen and electron pulling iodine coordinate, and the formation of radical cation (polaron) structure in polymer chain (on amine nitrogen) is enabled [27].

Electrical conductivities of the polymers and the changes of these values as a function of doping time with iodine were determined and shown in Fig. 9. Diaz et al. [28] suggested the doping mechanism of Schiff base polymers. According to doping mechanism, nitrogen, being a very 

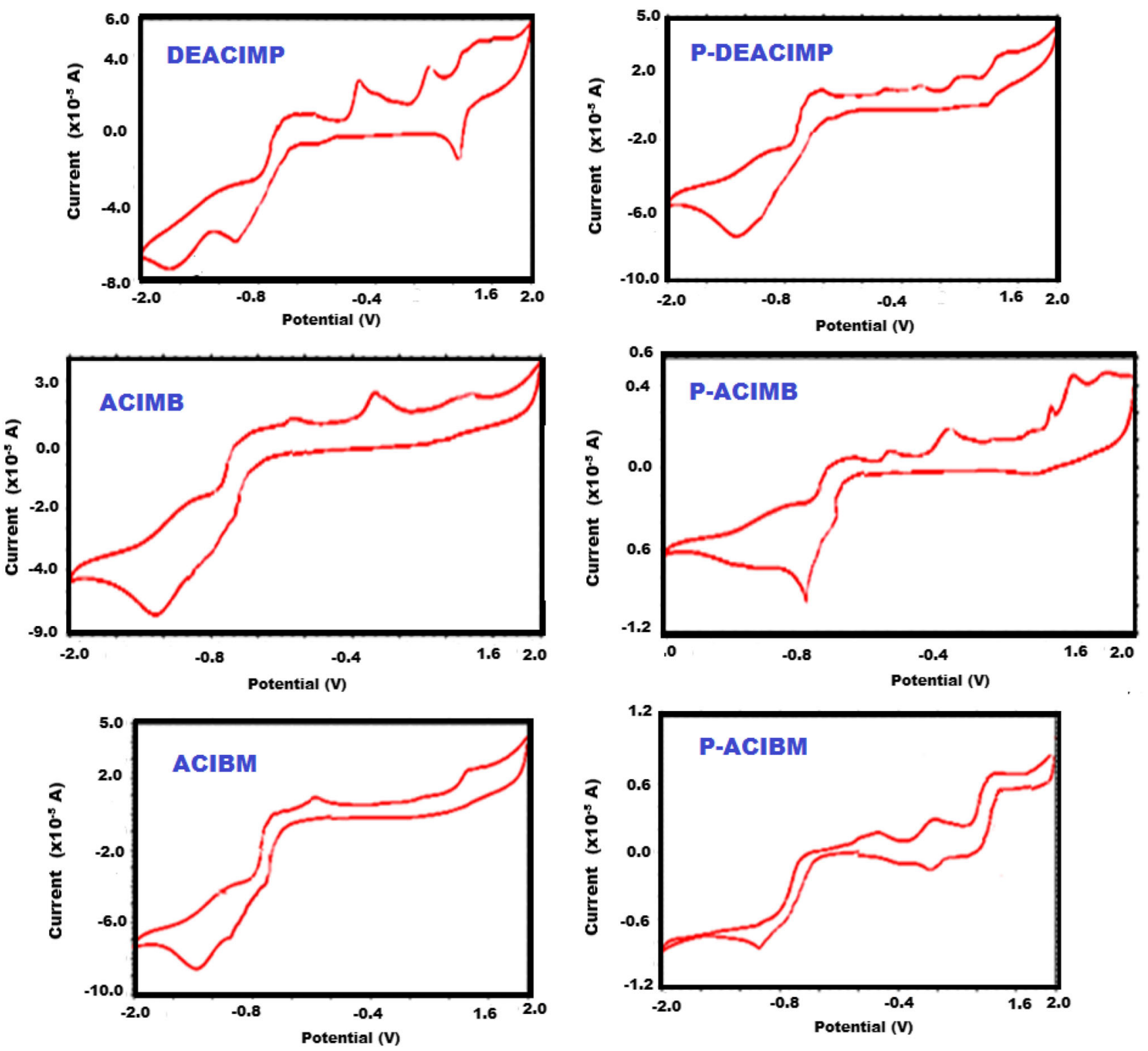

Fig. 8 Cyclic voltammograms of the monomers and polymers

electronegative element, is capable of coordinating with an iodine molecule (Scheme 2). Consequently, a chargetransfer complex between imine compound and dopant iodine forms and thus conductivity increases [29].

The conductivity values of the undoped P-DEACIMP, P-ACIBM, P-ACIMB polymers were about $4.3510^{-8}$, $4.2 \times 10^{-7}$ and $5.3 \times 10^{-7} \mathrm{~S} \mathrm{~cm}^{-1}$, respectively. After $120 \mathrm{~h}$ doping, the conductivity of P-DEACIMP, P-ACIBM, $\mathrm{P}$-ACIMB polymers were found to be around $1.78 \times 10^{-5}$, $5.13 \times 10^{-5}$ and $2.65 \times 10^{-5} \mathrm{~S} \mathrm{~cm}^{-1}$, respectively. According to these results, increasing of the conductivity values of polymers were observed as connected iodine doping time.

\section{Conclusions}

Schiff base with different position of $-\mathrm{OH}$ group was oxidatively polymerized in aqueous alkaline medium by $\mathrm{NaOCl}$ as oxidant. The structures of the monomers and polymers were confirmed by UV-Vis, FT-IR, ${ }^{1} \mathrm{H}$, and ${ }^{13} \mathrm{C}$ NMR spectroscopic techniques. According to ${ }^{1} \mathrm{H}-\mathrm{NMR}$ and ${ }^{13} \mathrm{C}-\mathrm{NMR}$ spectra, Schiff bases were polymerized by $\mathrm{C}-\mathrm{O}-$ $\mathrm{C}$ or $\mathrm{C}-\mathrm{C}$ binding. Iodine vapor-doped polymer P-DEACIMP gave the maximum electrical conductivity. The synthesized polymers have lower band gaps than the monomers because of polyconjugated structures. According to char $\%$ at $1000{ }^{\circ} \mathrm{C}$, the thermal stability of the 


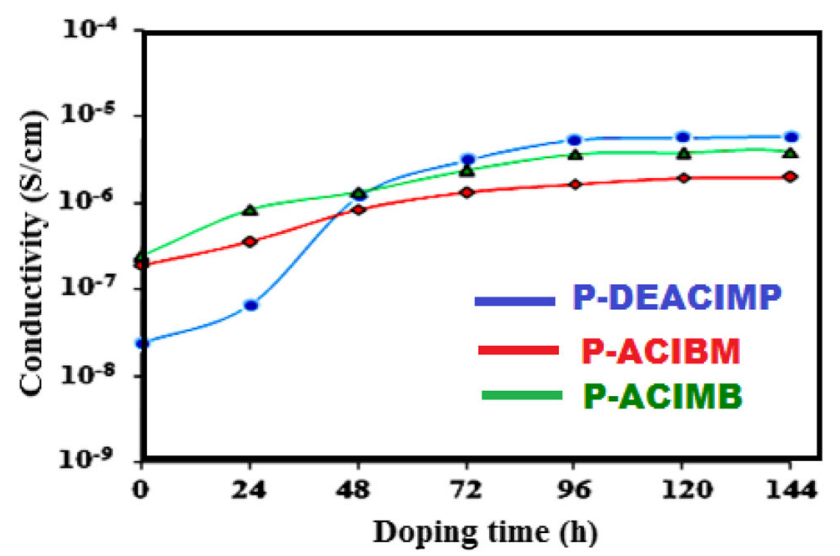

Fig. 9 Electrical conductivity changes of the polymers $\mathrm{I}_{2}$-doped at $25{ }^{\circ} \mathrm{C}$

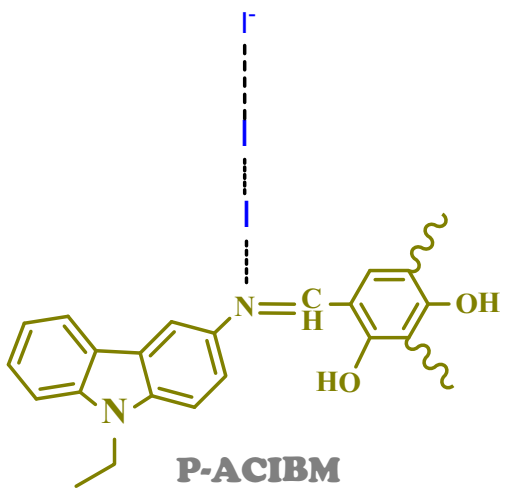

Scheme 2 The nitrogen atom coordination of iodine to the P-ACIBM

polymers was in the order P-ACIBM $>$ P-ACIMB $>$ PDEACIMP. The synthesized compounds were all soluble in common solvents such as DMF, THF and DMSO. Because of carbazole units in the structures of these polymers, both conductivity and thermal properties were better than that of other imine polymers in literature. Electrochemical band gap values of P-DEACIMP, P-ACIBM and P-ACIMB were found to be $2.58,1.54$ and $2.51 \mathrm{eV}$, respectively.

Open Access This article is distributed under the terms of the Creative Commons Attribution 4.0 International License (http://crea tivecommons.org/licenses/by/4.0/), which permits unrestricted use, distribution, and reproduction in any medium, provided you give appropriate credit to the original author(s) and the source, provide a link to the Creative Commons license, and indicate if changes were made.

\section{References}

1. Grigoras M, Antonoaia NC (2005) Synthesis and characterization of some carbazole-based imine polymers. Eur Polym J 41:10791089
2. Dineshkumar S, Muthusamy A (2016) Synthesis and spectral characterization of cross linked rigid structured Schiff base polymers: effect of substituent position changes on optical, electrical, and thermal properties. Polym-Plast Technol Eng 55:368-3788

3. El-Shekeil A, Al-Aghbari S (2004) DC electrical conductivity of some oligoazomethines. Polym Int 53:777-788

4. EI-Shekeil A, Hamid S, Ali DA (1997) Synthesis and characterization of some polyazomethine conducting polymers and oligomers. Polym Bull 39:1-7

5. Kaya İ, Bilici A (2006) Synthesis, characterization and thermal degradation of oligo-2-[(4-hydroxyphenyl) imino-methyl]-1naphtol and oligomer-metal complexes. J Macromol Sci Part A 43:719-733

6. Kaya İ, Bilici A (2007) Synthesis, characterization, thermal analysis, and band gap of oligo-2-methoxy-6-[(4-methylphenyl) imino] methyl phenol. J Appl Polym Sci 104:3417-3426

7. Yao Y, Zhang QT, Tour JM (1998) Synthesis of imine ridged planar poly(pyridinethiophene). Combination of planarization and intramolecular charge transfer in conjugated polymers. Macromolecules 31:8600-8606

8. Kaya İ, Koça S (2004) Synthesis, characterization and optimum reaction conditions of oligo-2-amino-3-hydroxypyridine and its Schiff base oligomer. Polymer 45:1743-1753

9. Mart H, Yürük H, Saçak M, Muradoğlu V, Vilayetoğlu AR (2004) The synthesis, characterization and thermal stability of oligo-4-hydroxybenzaldehyde. Polym Degrad Stab 83:395-398

10. Cimrova V, Ulbricht C, Dzhabarov V, Výprachtický D, Egbe DM (2014) New electroluminescent carbazole-containing conjugated polymer: synthesis, photophysics, and electroluminescence. Polymer 55:6220-6226

11. Nishat N, Khan SA, Rasool R, Parveen S (2011) Synthesis, spectral characterization and biocidal activity of thermally stable polymeric Schiff base and its polymer metal complexes. J Inorg Organomet Polym 21:673-681

12. Özbülbül A, Mart H, Tunçel M, Serin S (2006) A new soluble Schiff base polymer with a double azomethine group synthesized by oxidative polycondensation. Des Monomers Polym 9:169-179

13. Kaya İ, Vilayetoglu AR, Mart H (2001) The synthesis and properties of oligosalicylaldehyde and its Schiff base oligomers. Polymer 42:4859-4865

14. Zhang Y, Shibatomi K, Yamamoto H (2005) Lewis acid catalyzed highly selective halogenation of aromatic compounds. Synlett 18:2837-2842

15. Kaya İ, Aydın A (2012) A new approach for synthesis of electroactive phenol based polymer: 4-(2,5-di(thiophen-2-yl)-1Hpyrrol-1-yl)phenol and its oxidative polymer. Prog Org Coat 73:239-249

16. Erdik E (2008) Spectroscopic methods in organic chemistry, 5th edn. Gazi Press, Ankara, p 531

17. Özbülbül A (2006) Synthesis and characterization of new type oligomer Schiff bases with based oligophenol. Master theses, Institute of Science and Technology, Çukurova University, Adana, p 108

18. Kaya I, Aydın A (2011) Synthesis and characterization of the poly (amino phenol) derivatives containing thiophene in side chain: thermal degradation, electrical conductivity, optical-electrochemical, and fluorescent properties. J Appl Polym Sci 121:3028-3040

19. Kaya İ, Yıldırım M, Avcı A (2010) Synthesis and characterization of fluorescent polyphenol species derived from methyl substituted amino pyridine based Schiff bases: the effect of substituent position on optical, electrical, electrochemical, and fluorescence properties. Synth Met 160:911-920

20. Karakaplan M, Demetgül C, Serin S (2008) Synthesis and thermal properties of a novel Schiff base oligomer with a double 
azomethine group and its $\mathrm{Co}(\mathrm{II})$ and $\mathrm{Mn}(\mathrm{II})$ complexes. J Macromol Sci Part A 45:406-414

21. Colladet K, Nicolas M, Goris L, Lutsen L, Vanderzande D (2004) Low-band gap polymers for photovoltaic applications. Thin Solid Films 451:7-11

22. Kaya İ, Yıldırım M, Aydın A, Şenol D (2010) Synthesis and characterization of fluorescent graft fluorene-co-polyphenol derivatives: the effect of substituent on solubility, thermal stability, conductivity, optical and electrochemical properties. React Funct Polym 70:815-826

23. Kaya İ, Y1lmaz T (2017) Preparation and Characterization of poly (azomethines) containing ether and methylene bridges: photophysical, electrochemical, conductivity and thermal properties. J Fluorescence. doi:10.1007/s10895-016-1966-1

24. Cervini R, Li XC, Spencer G, Holmes AB, Moratti SC, Friend RH (1997) Electrochemical and optical studies of PPV derivatives and poly (aromatic oxadiazoles). Synth Met 84:359-360
25. Yang C, Jenekhe S (1995) Conjugated aromatic polyimines. 2. Synthesis, structure, and properties of new aromatic polyazomethines. Macromolecules 28:1180-1196

26. Spiliopoulos IK, Mikroyannidis JA (1996) Soluble, rigid-rod polyamide, polyimides, and polyazomethine with phenyl pendent groups derived from 4,4"-diamino-3,5,3",5"-tetraphenyl-p-terphenyl. Macromolecules 29:5313-5319

27. Kaya İ, Yıldırım M (2007) Synthesis, characterization, thermal stability and electrochemical properties of poly-4-[(2-methylphenyl)imino methyl]phenol. Eur Polym J 43:127-138

28. Diaz FR, Moreno J, Tagle LH, East GA, Radic D (1999) Synthesis, characterization and electrical properties of polyimines derived from selenophene. Synth Met 100:187-193

29. Kaya İ, Yildırım M (2009) Synthesis and characterization of graft copolymers of melamine: thermal stability, electrical conductivity, and optical properties. Synth Met 159:1572-1582 